\title{
Comparative assessment of extreme climate variability and human activities on regional hydrologic droughts in the Weihe River basin, North China
}

\author{
H. Shen ${ }^{1,2}$, L. Ren ${ }^{1}$, F. Yuan ${ }^{1}$, and X. Yang ${ }^{1}$ \\ ${ }^{1}$ State Key Laboratory of Hydrology-Water Resources and Hydraulic Engineering, \\ Hohai University, Nanjing, China \\ ${ }^{2}$ College of Hydrology and Water Resources, Hohai University, Nanjing, China \\ Correspondence to: L. Ren (njrll9999@126.com)
}

Received: 17 April 2015 - Accepted: 17 April 2015 - Published: 11 June 2015

\begin{abstract}
Drought is a comprehensive phenomenon not only resulting from precipitation deficits and climatic factors, but also being related to terrestrial hydrologic conditions and human activities. This paper investigated the relationships among regional hydrologic drought, climate extremes and human activities in the Weihe River basin, northwest China, where is also called Guanzhong Plain. First, the study period was divided into baseline and variation period according to the runoff trend analysis. Subsequently, the variable infiltration capacity (VIC) macroscale distributed hydrologic model was applied to reconstruct the natural runoff series in variation period. Furthermore, the effects of climate change and human activities on runoff were separated by the modelling results. Finally, standardized runoff index (SRI) and extreme climate indices were generated to quantatively assess the relationships among hydrologic droughts, climate extremes and human activity impacts. The results indicated that human activity impacts is a remarkable source of runoff reduction and represented an in-phase pattern of SRI-based drought severity and warm days. It also showed that the SRI-based floods and droughts characteristics are in good correlation with extreme precipitation.
\end{abstract}

\section{Introduction}

Over the past century, the global environment have witnessed an obvious change, which leads to accelerating the rate of water circulation, thereby resulting in high-frequency extreme events such as droughts and floods on a global scale (Sen and Balling, 2004). Many studies focusing on the hydrologic response to the changing environment showed that human activities has a profound impact on hydrologic processes, especially casusing runoff reduction (Ren et al., 2002; Wang et al., 2008). At the same time, recent years have seen the changes in extreme climate variability based on the observations in many regions of the world (Alexander et al., 2006). Drought is one of the costliest and most devastating natural hazards and attracts much attention these years. According to IPCC, drought in 21th century will be more intense and persistent in some regions of the world (Stocker et al., 2013), thus it is of great significance to evaluate drought under changing environment.

Precipitation deficit is being widely regarded as the basics causing droughts, thus many studies applied precipitation either individually (McKee et al., 1993) or in combination with other variables (temperature, Vicente-Serrano et al., 2010) to evaluate drought. However, these studies did not directly consider the runoff, which is another important component in water cycle and could be more prone to influenced by human beings, such as excessive river water uses and reservoirs. They may change the runoff production characteristics by affecting the underlying surface, or directly impact the water amounts. Moreover, persistent abnormal low flows in the river may also cause hydrologic drought. Therefore, hydrologic drought is linked closely with meteorological forcing and hydrologic conditions. In this study, a comparative analysis was applied to investigate the relationship among regional hydrologic droughts, climate extremes and human activities 
in the Weihe River basin, northwest China. The effects of climate variability and human activities on runoff were separated by variable infiltration capacity (VIC) hydrologic modelling. Then the standardized runoff index (SRI) was applied to evaluate droughts. Lastly, the relationship between the climate extremes and hydrologic drought was revealed.

\section{Data and methodology}

\subsection{Study area and datasets}

The physical area considered in this study is the portion of the Weihe River basin (Fig. 1) controlled by the Xianyang hydrologic station $\left(34.3^{\circ} \mathrm{N}, 108.7^{\circ} \mathrm{E}\right)$. The Weihe River is the largest tributary of the Yellow River with a watershed area of $46827 \mathrm{~km}^{2}$. Topographically, the elevation decreases from the west to the east, ranging from 3151 to $356 \mathrm{~m}$. The region is characterized by typical temperate continental climate, with abundant precipitation and high temperature in summer while conversely in winter.

The southeast part of the basin is called the Guanzhong Plain, where is a quite important agricultural production area. Note that there are eleven large irrigation areas (e.g. Baojixia, Jinghuiqu, Jiaokou, Taoqupo, Shitouhe, Fengjiashan, Yangmaowan, Donglei, Donglei, Luohuiqu and Shibaochuan) in the Guanzhong Plain with a total area greater than 801000 ha. Owing to the local climatology and the large amount of river water abstraction for irrigation, industrial and municipal use, this region suffered more frequent droughts and floods recently, thereby leading a reduction in agricultural output. In view of the water allocation and the ensurance of water use, it is urgent to investigate the relationship between the climate variability and regional drought as well as the influence of human society on hydrologic cycle.

The meteorological forcing data used to drive VIC model were provided by the China National Meteorological Centre (CNMC). This data sources included 44 meteorological stations within and around the basin (see in Fig. 1) from which daily precipitation, maximum and minimum air temperature and wind speed were provided. The daily runoff data at the Xianyang hydrologic station were provided by Ministry of Water Resources of China. Both the forcing data and the runoff series were from 1961 to 2012 and a quality control procedure was used for identifying errors in data processing, such as negative daily precipitation amounts were removed. For hydrologic modelling, forcing data were interpolated onto each 211 grid-cell $\left(0.25^{\circ} \times 0.25^{\circ}\right)$ using inverse distance weighted method (the exponent of distance is taken as 2 in this study).

Moreover, VIC model requires three GIS data layers: the digital elevation dataset obtained from Shuttle Radar Topography Mission (SRTM) at a spatial resolution of $90 \mathrm{~m}$ was used in the extraction of the river network and basin boundaries. The global $5 \mathrm{~s}$ soil profile map (Reynolds et al., 2000) provided from Food and Agriculture Organization (FAO)

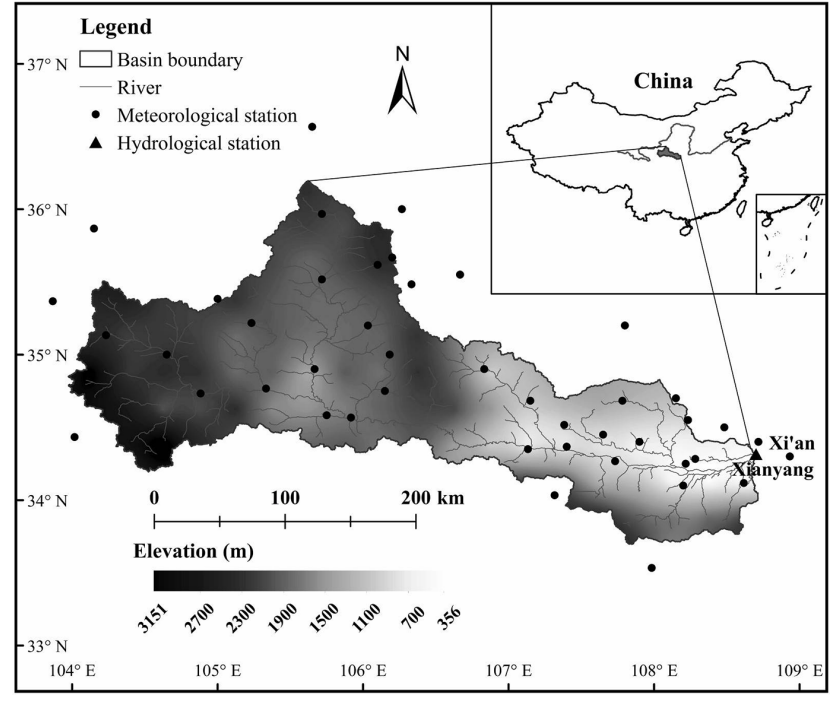

Figure 1. The location and topographic map of the study area and the observation stations.

was used to estimate the soil parameters. The global $1 \mathrm{~km}$ land cover classification dataset developed by Maryland University (Hansen et al., 2000) was used for evapotranspiration computation at sub-grids. In addition, the socio-economic data were retrieved from the Shaanxi Province Bureau of Statistics.

\subsection{Separation method based on hydrologic modelling}

Climate variability and human activity are two main reasons causing changes in runoff series. For a small basin, these two variables are generally been regarded as independent (Wang et al., 2008). In this study, according to the trend detection methods, the runoff series at the Xianyang hydrologic station was divided into two periods, a natural baseline period which influenced by less human activities and a human-induced variation period. The baseline period was applied for VIC model verification and then reconstructed the natural runoff series in the variation period. Therefore, we can separate the effects of climate variability and human activity on runoff as follows:

$$
\begin{aligned}
& \Delta Q_{\mathrm{tot}}=\Delta Q_{\mathrm{cv}}+\Delta Q_{\mathrm{ha}}=\bar{Q}_{2, \mathrm{obs}}-\bar{Q}_{1, \mathrm{obs}} \\
& \Delta Q_{\mathrm{cv}}=\bar{Q}_{2, \mathrm{sim}}-\bar{Q}_{1, \mathrm{sim}} \\
& \Delta Q_{\mathrm{ha}}=\Delta Q_{\mathrm{tot}}-\Delta Q_{\mathrm{cv}}=\left(\bar{Q}_{2, \mathrm{obs}}-\bar{Q}_{1, \mathrm{obs}}\right) \\
& -\left(\bar{Q}_{2, \operatorname{sim}}-\bar{Q}_{1, \operatorname{sim}}\right) \\
& I_{\mathrm{ha}}=\frac{\Delta Q_{\mathrm{ha}}}{\left|\Delta Q_{\mathrm{tot}}\right|} \times 100 \%, I_{\mathrm{cv}}=\frac{\Delta Q_{\mathrm{cv}}}{\left|\Delta Q_{\mathrm{tot}}\right|} \times 100 \%
\end{aligned}
$$


where $\Delta Q_{\text {tot }}$ is the total change of runoff and $\left|\Delta Q_{\text {tot }}\right|$ represents its absolute value; $\Delta Q_{\mathrm{cv}}$ and $\Delta Q_{\mathrm{ha}}$ are the runoff changes due to the effect of climate variability and human activity respectively; $\bar{Q}_{1, \text { obs }}$ and $\bar{Q}_{2, \text { obs }}$ are the observed mean annual runoff in baseline and variation period respectively; $\bar{Q}_{1, \text { sim }}$ and $\bar{Q}_{2, \text { sim }}$ are the simulated mean annual runoff in baseline and variation period respectively; $I_{\mathrm{ha}}$ and $I_{\mathrm{ha}}$ express the percentages of the effect of human activity and climate variability on runoff respectively.

\subsection{VIC model}

Variable infiltration capacity is a macroscale distributed hydrologic model which considers both the water and energy balances and has been successfully applied in many basins of China (Xie et al., 2007). The VIC model was implemented in the Weihe River basin at $0.25^{\circ}$ spatial resolution and daily temporal resolution from 1961 to 2012. Muskingum flow concentration method was adopted to produce the runoff at the Xianyang hydrologic station. The performance of VIC simulating discharge was quantified by the Nash-Sutcliffe model efficiency coefficient $\left(E_{\mathrm{NS}}\right)$ and the relative error $\left(E_{\mathrm{r}}\right)$ between multi-annual observations and simulations.

\subsection{Extreme climate indices and drought indices}

Seven extreme climate indices (cold days - TX10p), warm days (TX90p), cold nights (TN10p), warm nights (TN90p), annual precipitation (PrcpTOT), very wet days (R95p) and maximum 5-day precip (RX5day) - derived from daily air temperature and precipitation were computed at the $\mathrm{Xi}$ 'an meteorological station $\left(34.3^{\circ} \mathrm{N}, 108.9^{\circ} \mathrm{E}\right.$, see in Fig. 1). The details of the indices computation can refer to Alexander et al. (2006). SRI, which directly considers the runoff deficits, employed the algorithm of standardized precipitation index (SPI) that firstly fitting the accumulative runoff series to a non-standardized distribution at different time scales and then transforming it to a standardized normal distribution. They represent the hydrologic drought at different time scales. In this study, a two-parameter log-normal distribution was selected by Kolmogorov-Smirnov goodness-of-fit test. The detailed SRI computation procedure and the corresponding drought classification can refer to Mckee et al. (1993) and Shukla and Wood (2008).

\subsection{Analysis methods}

The non-parametric Pettitt test (Pettitt, 1979) and the precipitation-runoff double cumulative curve (DCC) were adopted to detect the change point of runoff series.

The cross wavelet analysis is a powerful method in testing correlation between two time series. In this study, this method was employed to depict the relationship between the extreme climate variability and hydrologic drought. The instruction of the method can refer to Grinsted et al. (2004).

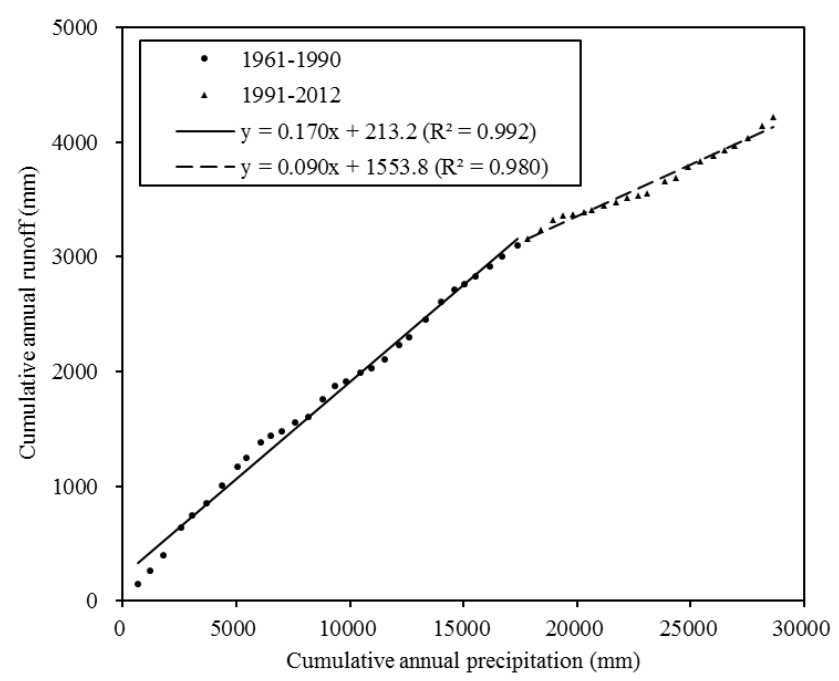

Figure 2. Precipitation-runoff double cumulative curve of the Weihe River basin.

\section{Results and discussion}

\subsection{Hydrologic modelling based on VIC}

Long-term trends in hydrologic processes may affected by climate variability and human activity. Detecting the trends in these processes, such as runoff, could help confirm the start of human-induced variation period. The Pettitt and DCC (Fig. 2) tests show a change-point of annual runoff series in 1990. Therefore, 1961-1990 was taken as the baseline period during which the effect of human activity on runoff was less recognized. The period from 1991 to 2012 was considered as the variation period. Then 1961-1980 was the calibration period and 1981-1990 was the validation period.

Figure 3 shows the comparison between the monthly observed and simulated runoff at the Xianyang hydrologic station. The values of $E_{\mathrm{NS}}$ and $E_{\mathrm{r}}$ are 0.78 and $-3.9 \%$ of the calibration period, and 0.84 and $4.78 \%$ of the validation period, respectively. It reflects a good agreement in the simulated and observed runoff series. Then the well verified VIC was applied to reconstruct the natural runoff series of the human-induced variation period, with the actual meteorological data as input.

\subsection{Effects of climate variability and human activities on runoff}

With the reconstructed natural runoff series in the variation period, it is possible to quantitatively evaluate the hydrologic response to the climate variability and human activities. As shown in Fig. 3, the observed runoff shows a notable reduction after 1990, compared with the reconstructed runoff. Specifically, the total change, changes due to climate variability and human activity in mean annual runoff were $-78.3,-25.1$ and $-53.2 \mathrm{~mm}$. Thus showing that hu- 


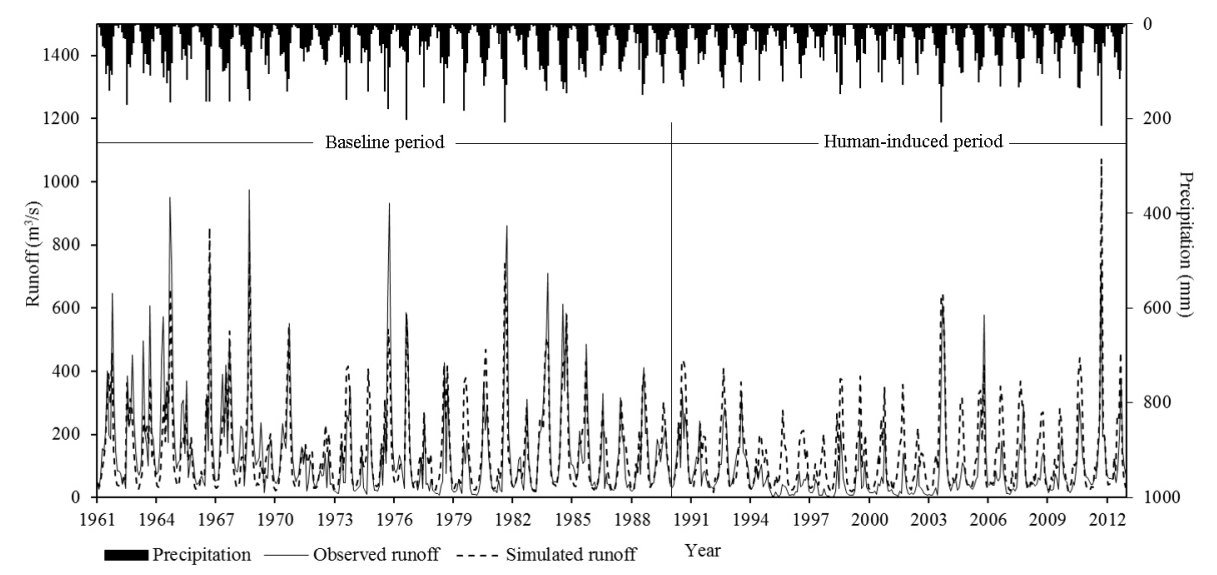

Figure 3. Monthly observed and VIC-simulated runoff for baseline (1961-1990) and human-induced (1991-2012) period at the Xianyang hydrologic station.

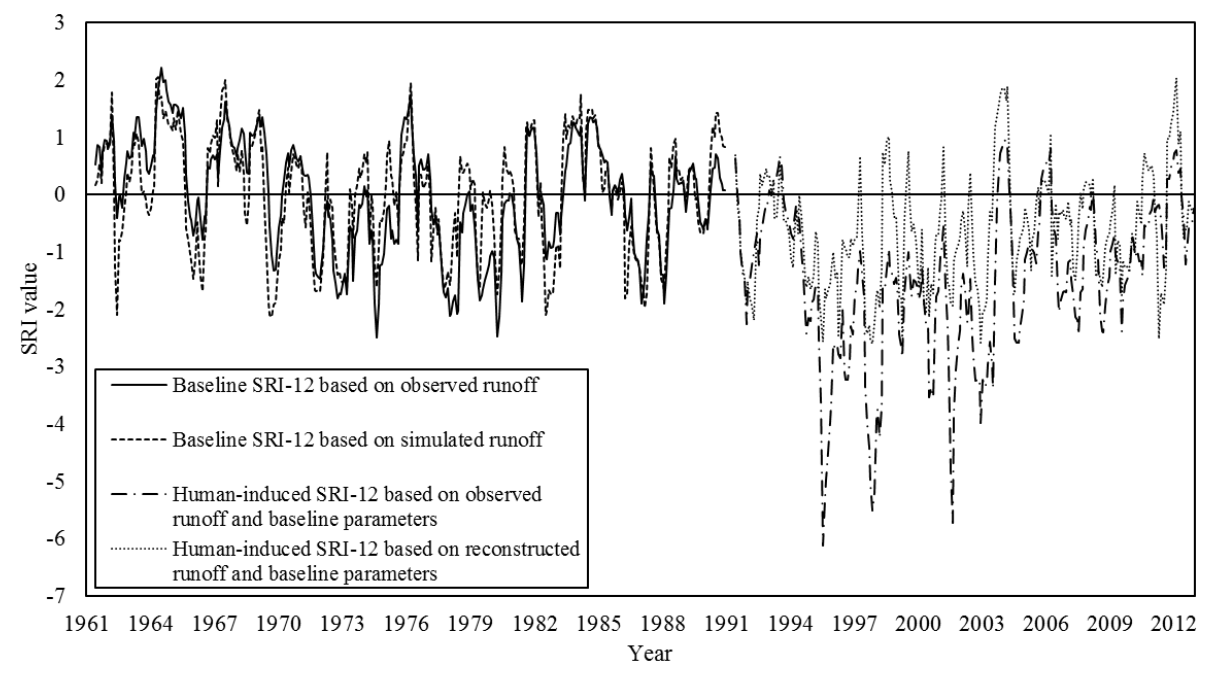

Figure 4. Standardized runoff index time series of 12-month accumulative runoff in baseline and variation periods at the Xianyang hydrologic station.

man activity was the dominant factor for $68 \%$ reduction in runoff. The main reason resulting in the significant runoff reduction was an increase of water demand in agriculture and industry. It is statistics that there were 403 reservoirs (with total storage more than $1.6 \times 10^{9} \mathrm{~m}^{3}$ ) in the Guanzhong Plain and 404670 ha irrigation area. Meanwhile, there are many water and soil conservation facilities in the basin to control the soil erosion, which may reduce the flood peak and increase the evaporations. It indicates the deep impacts of human activity on runoff reduction.

\subsection{Hydrologic drought evolution}

Similar with hydrological modelling, we firstly calculated the standardized runoff index in the baseline period based on the observed and simulated runoff respectively, then applied the baseline parameters to calculate the SRIs in variation period.
Figure 4 indicates a good relevance between the observationbased and simulation-based SRI-12 in baseline period. However, in the variation period the observation-based SRI-12 decreased significantly. Owing to the intense human activities after 1990s, the runoff production characteristics were deeply influenced and changed, letting the runoff series no longer being consistent with the former period. Thereby sharp biases appeared when employing the baseline parameters to fit the human-induced accumulative runoff series, thus in Fig. 4 some SRI values less than -3.0 should be regarded as outliers. Similar situations also existed in other temporal SRIs which are not all listed here. All these results indicate that human activity impacts is a remarkable source of runoff reduction and hydrologic droughts. 

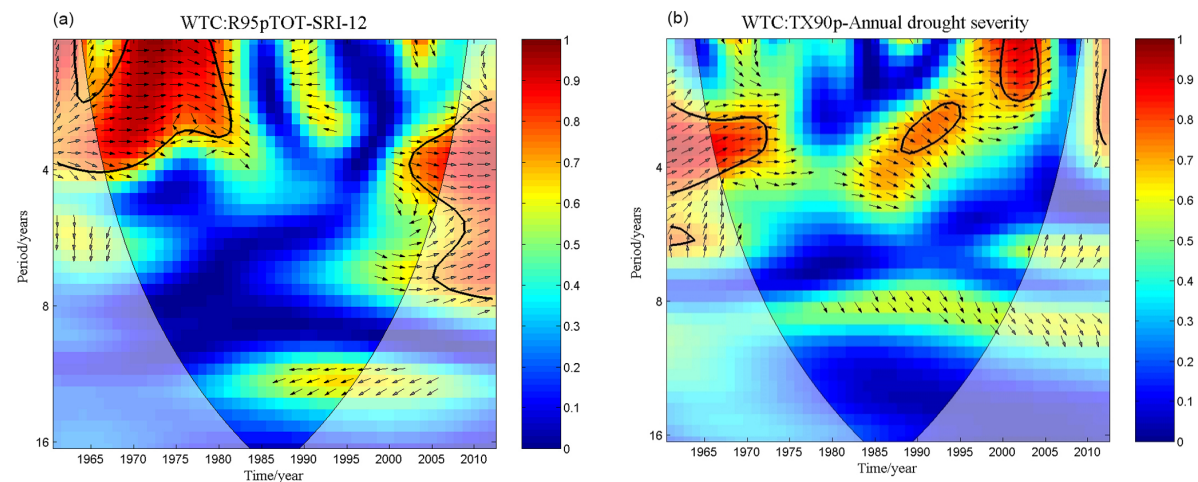

Figure 5. Squared wavelet coherence spectrum (a) between the R95pTOT (i.e. (R95p/PrcpTOT) $\times 100 \%$ ) and SRI-12 based on simulated runoff; and (b) between the TX90p (warm days) and annual drought severity based on SRI-12. The $5 \%$ significance level against red noise is shown as a thick contour. All significant sections show in-phase behaviour.

\subsection{Relationship between climate extremes and hydrological drought}

The squared wavelet coherence spectrum (WTC) of extreme climate indices and drought indices are shown in Fig. 5. The $5 \%$-significance sections in both the two figures show inphase relationship between the two examined series. Figure $5 \mathrm{a}$ indicates that higher contribution from very wet days (R95pTOT) may lead to a wetter condition, thus there is an in-phase pattern with SRI-12. The oscillations varied from 1 to 5 years, due to the SRI-12 only considers the water deficits in a relatively short time scale. Figure $5 b$ reflects only in three sections do the significant in-phase pattern between warm days and drought severity exist. It also demonstrates that regional warming trend may intensify the droughts.

Above all, the extreme climate variability do have an influence on hydrological drought. But it is not much to the effect of human activity.

\section{Conclusions}

This study was focused on investigating the relationships among the climate extremes, human activity and regional hydrological drought based on hydrologic modelling and drought assessment in the Weihe River basin, northwest China. The major conclusions are listed as follows.

a. Annual runoff of the Weihe River basin has a significant decreasing trend after 1990s; through Pettitt and DCC tests, an abrupt change point reflecting the intensified effect of human activity on runoff was detected to have occurred in 1990.

b. Reconstructed natural runoff series of 1991-2012 based on VIC model was employed to separate the effects of climate variability and human activities on runoff, showing that human activities was the dominant factor for runoff reduction; the reduction percentages due to climate variability were $32 \%$. c. Drought evolution based on the observed runoff and simulated runoff at the Xianyang hydrologic station in baseline and variation periods shows that the observation-based SRI decreased sharply after 1990s. Compared with the model-reconstructed runoff-based SRI, the dereasing trend was mostly due to the impacts of human activity.

d. Correlation analysis between extreme climate indices and hydrologic drought reflect in-phase relevances both of the increasing precipitation with SRI-12 and the increasing warm days with drought severity.

e. Quantifying the effects of climate variabity and human activity on regional hydrologic drought will contribute to regional water resources assessment and management. The Guanzhong Plain is an important agricultural production area, thus proposing orderly human activities is essential for water resource's sustainable development as well as alleviating hydrologic drought.

Acknowledgements. This work was financially supported by the national key technology $\mathrm{R} \& \mathrm{D}$ program of China (Grant 2013BAC10B02), the National Natural Science Foundation of China (Grant No. 41323001 and No. 41201031) and Special Basic Research Fund for Methodology in Hydrology under Grant no. 2011IM011000 by Ministry of Sciences and Technology, P. R. China. The work was also funded by 111 Project under Grant no. B08048 by Ministry of Education and State Administration of Foreign Experts Affairs, P. R. China. The authors would like to express their appreciation for the grants received to aid this research. 


\section{References}

Alexander, L. V., Zhang, X., Peterson, T. C., Caesar, J., Gleason, B., Klein Tank, A. M. G., and Vazquez-Aguirre, J. L.: Global observed changes in daily climate extremes of temperature and precipitation, J. Geophys. Res.-Atmos., 111, D05109, doi:10.1029/2005JD006290, 2006.

Grinsted, A., Moore, J. C., and Jevrejeva, S.: Application of the cross wavelet transform and wavelet coherence to geophysical time series, Nonlin. Processes Geophys., 11, 561-566, doi:10.5194/npg-11-561-2004, 2004.

Hansen, M. C., DeFries, R. S., Townshend, J. R., and Sohlberg, R.: Global land cover classification at $1 \mathrm{~km}$ spatial resolution using a classification tree approach, Int. J. Remote. Sens., 21, 13311364, 2000.

McKee, T. B., Doesken, N. J., and Kleist, J.: The relationship of drought frequency and duration to time scales, Proceedings of the 8th Conference on Applied Climatology, Boston, MA, Am. Meteorol. Soc., 17, 179-183, 1993.

Pettitt, A. N.: A non-parametric approach to the change-point problem, Appl. Stat., 28, 126-135, 1979.

Ren, L., Wang, M., Li, C., and Zhang, W.: Impacts of human activity on river runoff in the northern area of China, J. Hydrol., 261, 204-217, 2002.

Reynolds, C. A., Jackson, T. J., and Rawls, W. J.: Estimating soil water capacities by linking the Food and Agriculture Organization Soil map of the world with global pedon databases and continuous pedotransfer functions, Water. Resour. Res., 36, 36533662,2000 .
Sen, R. S. and Balling, R. C.: Trends in extreme daily precipitation indices in India, Int. J. Climatol., 24, 457-466, 2004.

Shukla, S. and Wood, A. W.: Use of a standardized runoff index for characterizing hydrologic drought, Geophys. Res. Lett., 35, L02405, doi:10.1029/2007GL032487, 2008.

Stocker, T. F., Qin, D., Plattner, G. K., Collins, M., Knutti, R., Arblaster, J., Dufresne, J., Fichefet, T., Friedlingstein, P., and Wehner, M.: IPCC, 2013: climate change 2013: the physical science basis, Contribution of working group I to the fifth assessment report of the intergovernmental panel on climate change, Long-term Climate Change: Projections, Commitments and Irreversibility, Cambridge Univ. Press, Cambridge, UK, and New York, USA, 2013.

Vicente-Serrano, S. M., Beguería, S., and López-Moreno, J. I.: A multiscalar drought index sensitive to global warming: the standardized precipitation evapotranspiration index, J. Climate, 23, 1696-1718, 2010.

Wang, G., Zhang, J., Ruimin, H. E., and Jiang, N.: Runoff reduction due to environmental changes in the Sanchuanhe river basin, Int. J. Sediment. Res., 23, 174-180, 2008.

Xie, Z., Yuan, F., Duan, Q., Zheng, J., Liang, M., and Chen, F.: Regional parameter estimation of the VIC land surface model: Methodology and application to river basins in China, J. Hydrometeorol., 8, 447-468, 2007. 